DOI: $10.20472 /$ IAC.2018.935.019

\author{
PRZEMYSLAW GROBELNY \\ Uniwersytet Ekonomiczny w Poznaniu, Poland \\ MACIEJ STRADOMSKI \\ Poznan University of Economics and Business, Poland \\ PIOTR STOBIECKI \\ Poznan University of Economics and Business, Poland
}

\title{
DETERMINANTS OF MERGER AND ACQUISITION ACTIVITY IN POLAND
}

\begin{abstract}
:
Despite the increasing importance of the emerging mergers and acquisitions ( $M \& A$ ) markets, the theoretical backgrounds of factors determining the level of activity of enterprises in taking up consolidation processes have not been adequately recognized. Not much attention has yet been paid in global researches to those markets for corporate control which are at earlier stage of development than highly mature markets with long history, such as the US, UK, Germany, or Japan. The primary purpose of the research is to identify the factors determining the level of activity on the $M \& A$ market in Poland, the leading M\&A market among CEE countries. Analysis covers the impact of factors identified in prior researches conducted on mature corporate control markets on the degree of activity on the M\&A market, as well as unique factors selected for the Polish market. According to the prevailing theoretical paradigm, particular markets - due to their institutional environment and degree of development - have a specific set of factors that determine their tendency for exogenous growth and acquisitions by other market players, such as investment funds or individual investors. Research commences with structuring, classification and analysis of the current state of knowledge. With the use of descriptive methods, the objective of identifying and characterizing the collection of universal factors determining M\&A market activity has been achieved. Reasoning on specific research problems has been proceeded using deduction, followed by statistical analysis to test the formulated hypothesis. With the use of relevant statistical and econometric methods, including multiple regression analysis, a relationship has been sought between the number of $M \& A$ transactions in Poland and the previously identified and selected explanatory variables and groups thereof. The results of regression analysis have been supplied with results of relative value analysis in order to determine, whether importance of national specific factors in explaining the dynamics of $M \& A$ deals is greater than universal factors.

Both the applied methodology and the extent of contemplated research in terms of space and time is innovative for an emerging $M \& A$ market. Unlike such areas as transaction efficiency, choice of payment method in acquisition, or business valuation in $M \& A$ processes, no comprehensive research has yet been carried out on factors determining the activity on the Polish corporate control market involving state-of-the-art econometric analysis.
\end{abstract}

\section{Keywords:}

Mergers and Acquisitions, M\&A, emerging market, CEE, Poland

JEL Classification: G34, G10, G39 